LETTERS TO THE EDITOR

\title{
Literacy Medication Labels
}

To the Editor:- In reference to a recent study titled: "Improving patient understanding of prescription drug label instructions" ${ }^{11}$ by Davis and colleagues, published online, we would like to emphasize the importance of the findings in this article and share the results of a pilot study we conducted in California in 2001-2002 on the inclusion of indication for use of medication on the prescription label and its impact on adherence and medication-taking confidence as perceived by elderly patients. In light of recent legislation passed in California mandating California State Board of Pharmacy to adopt a standardized prescription label by January $1,2011,{ }^{2}$ we believe this issue of prescription labeling will become more prominent.

Our study was exploratory in nature and used a prospective pre-post design. Elderly participants, 65 years or older were surveyed at baseline and after 6 months to assess change in adherence and confidence in taking medications. The intervention involved pharmacist adding the purpose of medication via words on the prescription labels with physician agreement since the California State Board of Pharmacy requires patient request and/ or prescriber agreement for this addition. The difference in pre-post scores was an indication of the effectiveness of the intervention.

A total of 92 patients were enrolled in the study of whom 77 completed both pre- and post-surveys. The average age of sample was $77.4( \pm 5.2)$ years. Only $24 \%$ of patients reported having trouble remembering what the medication was for when asked prior to the study. However, 93\% of the patients affirmed that having the indication on the label would help them with taking their mediations. Almost all those who responded said it helped them recognize what the medication was for, and helped in distinguishing between medications and in taking the right amount of medication. Similarly $84.8 \%$ reported that it definitely

Published online April 16, 2009 increased their level of confidence in taking their medications. The study had to be closed down due to physician non-participation.

Although our study predated the Institute of Medicine report on Preventing Medication Errors, ${ }^{3}$ it added value in showing that patients were willing to have indication on the label and found it useful and beneficial in distinguishing medications and increasing confidence in taking them. In light of the California mandate, we have revived research in this area and are studying the effect of modified labeling on patient medication taking behavior.

Amir H. Zargarzadeh, PharmD, and Anandi V. Law, BPharm, PhD, College of Pharmacy, Western University of Health Sciences, $309 \mathrm{E}$, Second St., Pomona, CA 91766, USA; (e-mail: alaw@westernu.edu).

\section{REFERENCES}

1. Davis TC, Federman AD, Bass PF, Jackson RH, Middlebrooks M, Parker RM, Wolf MS. Improving patient understanding of prescription drug label instructions. J Gen Intern Med. 2008.

2. Standardizing medication labels: Confusing patients less, Workshop summary. P. 47. http://www.nap.edu/catalog/12077.html-accessed Nov 2008.

3. Institute of Medicine. In: Aspden P, Wolcott J, Bootman L, Cronenwett LR, eds. Preventing medication errors. Washington DC. National Academy Press; 2006.

J Gen Intern Med 24(6):779

DOI: $10.1007 / \mathrm{s} 11606-009-0940-x$

(C) Society of General Internal Medicine 2009 